\title{
Effect of ocean acidification on the fatty acid composition of a natural plankton community
}

\author{
E. Leu ${ }^{1, *}$, M. Daase ${ }^{1}$, K. G. Schulz ${ }^{2}$, A. Stuhr ${ }^{2}$, and U. Riebesell ${ }^{2}$ \\ ${ }^{1}$ Norwegian Polar Institute, FRAM Centre, 9296 Troms $\varnothing$, Norway \\ ${ }^{2}$ Helmholtz Centre for Ocean Research Kiel (GEOMAR), 24105 Kiel, Germany \\ * now at: Alfred-Wegener-Institute for Polar and Marine Research, Am Handelshafen 12, \\ 27570 Bremerhaven, Germany \\ Correspondence to: E. Leu (eva.leu@awi.de)
}

Received: 17 May 2012 - Published in Biogeosciences Discuss.: 9 July 2012

Revised: 23 December 2012 - Accepted: 15 January 2013 - Published: 20 February 2013

\begin{abstract}
The effect of ocean acidification on the fatty acid composition of a natural plankton community in the Arctic was studied in a large-scale mesocosm experiment, carried out in Kongsfjorden (Svalbard, Norway) at $79^{\circ} \mathrm{N}$. Nine mesocosms of $\sim 50 \mathrm{~m}^{3}$ each were exposed to 8 different $p \mathrm{CO}_{2}$ levels (from natural background conditions to $\sim 1420 \mu \mathrm{atm}$ ), yielding $\mathrm{pH}$ values (on the total scale) from $\sim 8.3$ to 7.5 . Inorganic nutrients were added on day 13 . The phytoplankton development during this 30-day experiment passed three distinct phases: (1) prior to the addition of inorganic nutrients, (2) first bloom after nutrient addition, and (3) second bloom after nutrient addition. The fatty acid composition of the natural plankton community was analysed and showed, in general, high percentages of polyunsaturated fatty acids (PUFAs): 44-60\% of total fatty acids. Positive correlations with $p \mathrm{CO}_{2}$ were found for most PUFAs during phases 2 and/or 3 , with the exception of 20:5n3 (eicosapentaenoic acid, EPA), an important diatom marker. These correlations are probably linked to changes in taxonomic composition in response to $p \mathrm{CO}_{2}$. While diatoms (together with prasinophytes and haptophytes) increased during phase 3 mainly in the low and intermediate $p \mathrm{CO}_{2}$ treatments, dinoflagellates were favoured by high $\mathrm{CO}_{2}$ concentrations during the same time period. This is reflected in the development of group-specific fatty acid trophic markers. No indications were found for a generally detrimental effect of ocean acidification on the planktonic food quality in terms of essential fatty acids.
\end{abstract}

\section{Introduction}

Ocean acidification occurs as a consequence of increasing atmospheric $\mathrm{CO}_{2}$ concentrations, and is thought to represent a major threat for some groups of marine organisms. Due to the temperature-dependence of gas solubility in seawater, high latitudes are especially sensitive to anthropogenic carbon dioxide. Higher $\mathrm{CO}_{2}$ solubility at lower temperatures results in naturally low buffering capacity, leading to a lower carbonate ion saturation state (Broecker et al., 1979) and an increase in temporal pH variability (Steinacher et al., 2009). This potentially aggravates the threat of ocean acidification to organisms relying on carbonate or aragonite structures at high latitudes (see Lischka et al. (2011) and references therein). Little is known about the impact of ocean acidification on Arctic pelagic communities, and this study presents the first experimental approach to address this question in situ at a high Arctic location.

Storing metabolic energy in the form of lipids is one of the most wide-spread and important adaptive traits among organisms living at high latitudes, characterized by an extreme seasonality in environmental conditions and food supply. Hence, the transfer of energy and biomass through the Arctic food web can be characterized as lipid-based. Most lipids consist mainly of fatty acids, hydrocarbon chains with varying numbers of double bonds. Among these fatty acids, some polyunsaturated fatty acids (PUFAs, with two or more double bonds) are essential metabolites. These are synthesized by algae only and have to be taken up via the diet by all other organisms. Both in field observations (Pond et 
al., 1996; Jonasdottir et al., 2005) and experimental studies (Jonasdottir et al., 2009; Klein Breteler et al., 2005), PUFAs were documented to be crucial for copepod egg production and hatching, as well as for proper development until reaching maturity. Also in fish, the essential role of PUFAs for successful recruitment and reproduction was shown by, e.g., Watanabe et al. (1983) and Sargent et al. (1995). A comprehensive overview on the biochemical aspects of trophic interactions can be found in Müller-Navarra (2008). Moreover, the fatty acid composition of membrane lipids controls membrane fluidity, and is therefore intrinsically linked to the functioning of all membrane-bound physiological processes, such as photosynthesis or respiration. The fatty acid composition of major algae groups varies due to differences in the genetically determined biosynthetic pathways for fatty acid synthesis. Consequently, the fatty acid composition of a natural plankton community will reflect its taxonomic composition in a biomass-dependent way. Based on this knowledge, fatty acids can be used as fatty acid trophic markers (FATM) (Dalsgaard et al., 2003). In addition, the relative amount of PUFAs produced by algae will depend strongly on the algal physiological state, and, hence the environmental conditions. Algal PUFA production is negatively affected by high irradiances (Thompson et al., 1990; Leu et al., 2006, 2010), low nutrient concentrations (Klein Breteler et al., 2005; Reitan et al., 1994), and high temperature (Thompson et al., 1992).

So far very few studies have examined the effect of ocean acidification on algal or planktonic fatty acid composition. All previous studies were carried out with unialgal cultures in the laboratory, with differing results: A first study was conducted by Tsuzuki et al. (1990), testing several species from different algal groups for changes in lipid class and fatty acid composition as a function of $p \mathrm{CO}_{2}$. In four out of seven species, no effects were found at all, and in general, no change in lipid class composition was observed between high and low $\mathrm{CO}_{2}$ treatments. Only green algae showed a $p \mathrm{CO}_{2}$-induced change in fatty acid composition. Carvalho and Malcata (2005) tried to optimize $\mathrm{n} 3$ fatty acid production in the prymnesiophyte Pavlova lutheri, and found an increase of total lipids at high $p \mathrm{CO}_{2}$, but relatively less PUFAs. The biochemical response of three different species of prymnesiophyte to increased $p \mathrm{CO}_{2}$ was studied by Fiorini et al. (2010), without finding a general decrease in food quality in terms of $n 3$ fatty acids. Riebesell et al. (2000) reported a substantial decline of all major PUFAs in Emiliania huxleyi as a function of increasing $p \mathrm{CO}_{2}$. Contrary to all these studies, Hoshida et al. (2005) described an accumulation of 20:5n3 (EPA) in Nannochloropsis as a response to elevated $p \mathrm{CO}_{2}$. A first study was performed on indirect effects of ocean acidification on grazers (copepods), mediated by trophic transfer from algae grown under elevated $\mathrm{CO}_{2}$ concentrations: the authors found strong negative effects of high $p \mathrm{CO}_{2}$, both with respect to the algal content of essential PUFAs, but also in the copepods' fatty acid composition, development and egg production rates (Rossoll et al., 2012). To our knowledge, no
Table 1. $\mathrm{pH}$ (on the total scale) and $p \mathrm{CO}_{2}$ levels in the nine mesocosms at the start and the end of the experimental period. No $\mathrm{CO}_{2}$ was added to mesocosms M3 and 7; they served as controls.

\begin{tabular}{lrrrr}
\hline & \multicolumn{2}{c}{ Initial (t8-t9) } & \multicolumn{2}{c}{ Final (t26-t27) } \\
\cline { 2 - 5 } Mesocosm & $\mathrm{pH}$ & $p \mathrm{CO}_{2}(\mu \mathrm{atm})$ & $\mathrm{pH}$ & $p \mathrm{CO}_{2}(\mu \mathrm{atm})$ \\
\hline 3 & 8.32 & 185 & 8.36 & 165 \\
7 & 8.31 & 185 & 8.37 & 160 \\
2 & 8.18 & 270 & 8.25 & 220 \\
\hline 4 & 8.05 & 375 & 8.15 & 290 \\
8 & 7.96 & 480 & 8.07 & 365 \\
1 & 7.81 & 685 & 7.94 & 500 \\
\hline 6 & 7.74 & 820 & 7.90 & 555 \\
5 & 7.64 & 1050 & 7.80 & 715 \\
9 & 7.51 & 1420 & 7.73 & 855 \\
\hline Fjord & 8.41 & 145 & 8.32 & 180 \\
\hline
\end{tabular}

previous attempts have been made to investigate the response of a natural community fatty acid composition to increased levels of $p \mathrm{CO}_{2}$.

In the framework of the large-scale mesocosm experiment in Ny-Ålesund (Svalbard) in summer 2010, we tested for the very first time the effect of ocean acidification on the fatty acid composition of a natural plankton community. The aim of this study was to describe how the fatty acid composition of a natural plankton community is affected by decreasing $\mathrm{pH} /$ increasing $\mathrm{CO}_{2}$ levels, with special emphasis on essential PUFAs. The study encompassed three phases dominated by different algal communities and characterized by a shortage of inorganic nutrients at the start of the experiment, and growth under nutrient replete conditions following artificial nutrient addition halfway through the experiment.

\section{Materials and methods}

\subsection{Study area}

Kongsfjorden is a fjord on the western coast of Spitsbergen at a latitude of almost $79^{\circ} \mathrm{N}$ (Svalbard, Norway). It is $20-\mathrm{km}$ long with a width ranging from 4 to $10 \mathrm{~km}$ and a maximum depth of $400 \mathrm{~m}$. Kongsfjorden is influenced by both Atlantic and Arctic water masses, and receives a discharge of freshwater and sediments from the adjacent glaciers that varies seasonally, peaking in the summer. During winter, the inner part of the fjord will typically have a land-fast ice cover. The formation, thickness and break-up of this ice cover have a substantial interannual variation, linked to the climatic and hydrographic conditions. A detailed review of the physical environment of Kongsfjorden is given by (Svendsen et al., 2002). The mesocosm experiment was carried out close to the settlement of $\mathrm{Ny}$-Ålesund on the southern shore of Kongsfjorden at $78^{\circ} 56.2^{\prime} \mathrm{N}$ and $11^{\circ} 53.6^{\prime} \mathrm{E}$. 


\subsection{Experimental set-up}

A detailed description of the experimental setup, its deployment and technical features can be found in (Riebesell et al., 2013). In brief, nine mesocosms consisting of 17-m long flexible plastic bags fixed to a buoyancy and stability rack were deployed in Kongsfjorden for an experimental period of about 30 days. In each mesocosm, $\sim 50 \mathrm{~m}^{3}$ of natural seawater were enclosed at the start of the experiment. When initially lowering the plastic bags, a screen with $3 \mathrm{~mm}$ mesh size was attached to the bottom of the bags, thereby excluding organisms above this size from enclosure. The mesocosms were deployed at $t=-7$ days, and closed two days later $(t=-5)$, in order to minimize differences in starting conditions among mesocosms which may arise from patchiness in plankton distributions during lowering of the mesocosm bags. $\mathrm{CO}_{2}$ enrichment was achieved through the addition of $\mathrm{CO}_{2}$-saturated seawater to seven out of nine mesocosms in five steps, between day -1 and day 4 . The remaining two mesocosms, $\mathrm{M} 3$ and $\mathrm{m} 7$, were not manipulated and served as controls. The initial and final $\mathrm{CO}_{2}$ and $\mathrm{pH}$ levels for all nine mesocosms are provided in Table 1 (see also Bellerby et al., 2013).

On day 13, nitrate, phosphate and silicate were added to all mesocosms to increase concentrations by $5,0.31$ and $2.5 \mu \mathrm{mol} 1^{-1}$, respectively, corresponding to approx. $50 \%$ of the winter concentrations measured in Kongsfjorden (Leu et al., 2006) Most parameters (as presented in the other contributions to this special volume) were sampled daily using a depth-integrated water sampler (IWS, Hydrobios), covering the upper $12 \mathrm{~m}$ of the water column. Due to the large sample volume required, samples for planktonic fatty acid composition were taken on days 4,8 , and on every other day between days 11 and 25 .

\subsection{Analyses}

\subsubsection{Fatty acid composition}

For fatty acid analyses, $3 \mathrm{~L}$ of seawater from the various treatments were filtered onto a pre-combusted GF/F-filter (Whatman) that was immediately put into an $8 \mathrm{~mL}$ glass vial filled with dichloromethane: methanol $(2: 1, v / v)$, and frozen at $-20^{\circ} \mathrm{C}$. Filters were stored frozen until analysis. They were then crushed by ultrasonification and extracted in dichloromethane: methanol $(2: 1, v / v)$ following the method after Folch et al. (1957). Prior to extraction, an internal standard was added (23:0). This standard was used to quantify the amount of single fatty acids in the sample by comparing the area/amount of standard with the area of our analytes (fatty acids). For gas liquid chromatography of fatty acids, methyl esters were prepared from aliquots of the extracted microalgae by transesterification with $3 \%$ sulfuric acid in methanol for $4 \mathrm{~h}$ at $80^{\circ} \mathrm{C}$. After extraction with hexane, fatty acid methyl esters (FAME) were analyzed with a gas liquid chromatograph (Agilent 6890, Agilent GmbH, Waldbronn, Germany) on a capillary column $(60 \mathrm{~m} \times 0.25 \mathrm{~mm}$ I.D.; film thickness: $0.25 \mu \mathrm{m}$; liquid phase: DB-FFAP (Agilent)) using temperature programming (Injection: splitless at $250^{\circ}$, detection: FID at $280^{\circ} \mathrm{C}$ ). FAMEs were identified by comparison with known standard mixtures. The total amount of lipids is referred to as the sum of total fatty acid methyl esters.

The following fatty acids were used as taxonomic marker fatty acids (modified after, Dalsgaard et al., 2003 and Ackman et al., 1968):

$$
\begin{aligned}
& \text { - Diatoms: } 16: 1 \mathrm{n} 7+16: 4 \mathrm{n} 1+20: 5 \mathrm{n} 3 \\
& \text { - Dinoflagellates: } 18: 4 \mathrm{n} 3+18: 5 \mathrm{n} 3+22: 6 \mathrm{n} 3 \\
& \text { - Chlorophytes: } 18: 2 \mathrm{n} 6+18: 3 \mathrm{n} 3
\end{aligned}
$$

Indicative for bacterial biomass are odd-numbered and branched chained fatty acids, e.g. i15:0 and a15:0.

\subsubsection{Planktonic biomass quantification: Chlorophyll $a$ and particulate carbon}

Chlorophyll a (Chl $a)$ was determined fluorometrically on depth-integrated (0-12 $\mathrm{m}$ depth) water samples, filtered on GF/F-filters, according to Welschmeyer (1994). For the method description on particulate carbon analysis, see Schulz et al. (2013).

\subsubsection{Sampling and sorting of cirripedia nauplii}

Zooplankton samples were taken with an apstein net with a diameter of $17 \mathrm{~cm}$ and a mesh size of $55 \mu \mathrm{m}$ (see Niehoff et al., 2012). Cirripedia nauplii were sorted alive under a stereomicroscope using a glass pipette, transferred to glass vials in groups of 65 and immediately deep-frozen at $-80^{\circ} \mathrm{C}$.

\subsubsection{Statistical analyses}

Linear regression analyses were used to investigate the relationship between proportions of different fatty acid markers $(\%)$ and $\mathrm{CO}_{2}$ level $(\mu \mathrm{atm})$ in the different mesocosms at different phases of the experiment. The duration of the experiment was divided into three phases with phase 1 starting at day 4 and lasting until day 12, phase 2 starting day 13 until day 21 and phase 3 starting day 22 and lasting to the end of the experiment. This division into three phases was based upon the observation of three distinct bloom events occurring during the time period of the experiment (see results), with distinctly differing features and responses towards the applied gradient in $p \mathrm{CO}_{2}$. An average of the proportion of the different fatty acid markers and the $\mathrm{CO}_{2}$ concentration in the different mesocosms was calculated for each phase. Principal component analysis (PCA) was used to obtain an overview of similarities in the fatty acid composition measured at the different days of the experiment. The PCA distributes the samples in an ordination space according to the 
fatty acid composition along orthogonal principal components that are extracted to explain as much of the variance as possible. The response variables are indicated by arrows in the direction of increased importance in separating the samples. The length of the arrows indicates the importance of the variables in explaining the variation on the samples (long arrow $=$ high importance, short arrow $=$ low importance) . The PCA was run on the entire dataset (including all FAs $>1 \%$, corresponding to the tables shown in the Supplement); for reasons of clarity, only selected FAs were displayed in the plot. All statistical analyses were done using R (R Development Core Team 2005).

\section{Results}

\subsection{General development of autotroph biomass (in terms of Chl $a$ )}

The development of fluorometrically determined Chl $a$ concentrations in the nine mesocosms is shown in Fig. 1. The bloom development during the experimental period can be divided into three phases: Phase 1 represents the phytoplankton development prior to the addition of inorganic nutrients (day 13). It was characterized by a nanophytoplankton community utilizing predominantly organic nutrients (Brussaard et al., 2013). After this bloom decreased, inorganic nutrients (nitrate, phosphate, silicate) were added, corresponding to $\sim 50 \%$ of typical winter concentrations. This induced a second bloom, lasting from day 13 to 21 , followed by a third bloom (day 22 to 30). The second bloom was dominated by picophytoplankton and rapidly controlled by microzooplankton and viruses, while the third bloom was dominated by nanophytoplankton (based on cell abundance), and by dinoflagellates, haptophytes and prasinophytes in terms of biomass. It declined as a result of nutrient depletion (Brussaard et al., 2013). Interestingly, the $p \mathrm{CO}_{2}$ levels in the different mesocosms yielded different effects in every bloom phase: during the first bloom, no treatment effect was observed. During the second bloom, $\mathrm{CO}_{2}$ effects were found on growth, nutrient uptake rates and pigment biosynthesis Schulz et al. (2013), with higher Chl $a$ values in the high $p \mathrm{CO}_{2}$ mesocosms. In the last bloom, the highest $\mathrm{Chl} a$ values were found in the intermediate and low $p \mathrm{CO}_{2}$ treatments. Furthermore, diatoms, haptophytes and prasinophytes were more abundant under low/intermediate $p \mathrm{CO}_{2}$ conditions, while dinoflagellates were favoured by high $\mathrm{CO}_{2}$ concentrations (Brussaard et al., 2013; Schulz et al., 2013). The temporal development of particulate carbon, nitrogen and phosphorus is described in detail by (Schulz et al., 2013).

\subsection{Planktonic fatty acid composition}

The planktonic fatty acid composition was characterized by comparatively high values of PUFAs throughout the entire

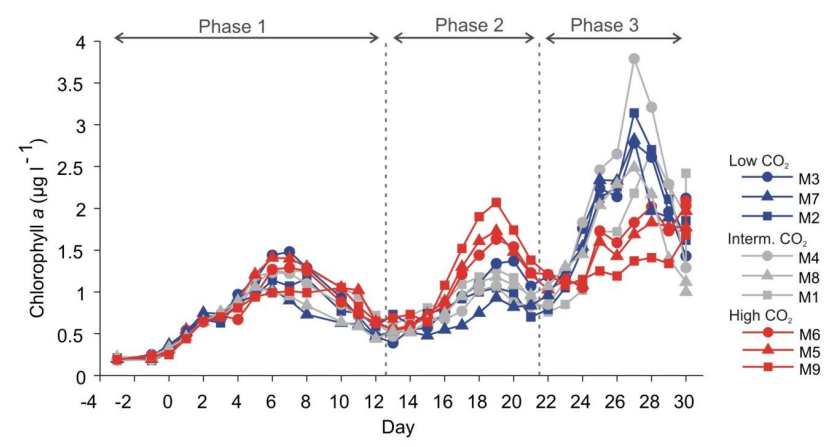

Fig. 1. Chlorophyll $a$ concentration $\left(\mu \mathrm{g} \mathrm{l}^{-1}\right)$ in the different mesocosms (M1-M9) and in the fjord during the experiment. Data from mesocosms with low $\mathrm{CO}_{2}$ concentration (170-270 $\mu \mathrm{atm}$ ), intermediate $\mathrm{CO}_{2}$ concentration (370-717 $\left.\mu \mathrm{atm}\right)$ and high $\mathrm{CO}_{2}$ concentration (544-1825 $\mu \mathrm{atm})$ are marked in blue, grey, and red, respectively. The different phases of the experiment are indicated (Phase $1=$ day -4 to 12 , Phase $2=$ day 13 to 21 , Phase $3=$ day 22 to 30$)$.

experimental period and within all treatments, ranging from 44 to $60 \%$ of total fatty acids (Fig. 2, Table sI). On day 4, the PUFA content among the different mesocosms varied between 44 and $55 \%$, while in most mesocosms the lowest values were found on day $8(46-50 \%)$, with the exception of mesocosm 9 (44\% on day 4). After that, an increase was observed in almost all mesocosms, with the highest values in the three high $p \mathrm{CO}_{2}$ treatments between days 19 and 25 (during the later part of phase 2, and phase 3). Among the n3 PUFAs, 20:5n3 (eicosapentaenoic acid, EPA) and 22:6n3 (docosahexaenoic acid, DHA) were most abundant, each accounting for up to $20 \%$ of total fatty acids (Fig. 2, Table sI). The percentages of EPA increased mainly during phase 3, whereas DHA rose most pronounced between days 8 and 18 (mainly phase 2). The relative abundance of C18 PUFAs $18: 4 \mathrm{n} 3$ and $18: 5 \mathrm{n} 3$ both declined during phase 3 ; the highest values of $18: 4 \mathrm{n} 3$ were observed on day 8 , followed by a continuous decline. 18:5n 3 increased from initially 4-5\% up to almost $14 \%$ throughout phases 1 and 2 , followed by a decline during phase 3 .

The overall PUFA content (in \% of total fatty acids) was significantly positively correlated with $p \mathrm{CO}_{2}$ in phases 2 and 3 (Fig. 3, Table 2). DHA was significantly negatively correlated with $p \mathrm{CO}_{2}$ during phase 1 , and strongly positively correlated during phase 3 . The latter was also found for the dinoflagellate markers $(18: 4 \mathrm{n} 3+18: 5 \mathrm{n} 3+\mathrm{DHA})$. The diatom markers $(16: 1 \mathrm{n} 7+16: 4 \mathrm{n} 1+\mathrm{EPA})$ showed a significant negative correlation with $p \mathrm{CO}_{2}$ in phases 2 and 3. For EPA alone, this correlation was only significant in phase 2 . Of all PUFAs, 18:5n3 was the one depicting the greatest changes and treatment-dependent differences, with the highest values found in the highest $p \mathrm{CO}_{2}$ treatment during phase 2 (Fig. 2).

The most important saturated fatty acid (SAFA) was 16:0, followed by 14:0, accounting for roughly 17 and $7 \%$, 
Table 2. Linear regression analyses of fatty acid markers (\%) against $p \mathrm{CO}_{2}$ ( $\mu$ atm) in different phases of the experiment. Proportion of different fatty acids markers and $p \mathrm{CO}_{2}$ levels were averaged over the time period of the three phases: Phase $1=$ day -4 to 12 , Phase $2=$ day 13 to 21 , Phase $3=$ day 22 to end. Entries in the Table give the estimates for the intercept and the slope, the $R^{2}$ value and the statistical significant level given as $\mathrm{p}$ values and indicated as $* * * p<0.001, * * 0.001<p<0.01, * 0.01<p<0.05$ ).

\begin{tabular}{crrrrrr}
\hline Phase & Fatty Acid & Intercept & Slope & $P$ & Sign. & $R^{2}$ \\
\hline 1 & PUFA & & & 0.144 & & \\
2 & PUFA & 52.01 & 0.003 & 0.035 & $*$ & 0.42 \\
3 & PUFA & 48.81 & 0.011 & 0.004 & $* *$ & 0.68 \\
1 & Diatom & & & 0.755 & & \\
2 & Diatom & 17.69 & -0.004 & 0.013 & $*$ & 0.56 \\
3 & Diatom & 28.84 & -0.014 & 0.020 & $*$ & 0.50 \\
1 & Dinoflagellates & & & 0.098 & & \\
2 & Dinoflagellates & & & 0.059 & & \\
3 & Dinoflagellates & 24.33 & 0.016 & 0.009 & $* *$ & 0.60 \\
1 & Chlorophyte & & & 0.138 & & \\
2 & Chlorophyte & 4.40 & 0.002 & 0.000 & $* * *$ & 0.86 \\
3 & Chlorophyte & & & 0.183 & & \\
1 & $18: 5 \mathrm{n} 3$ & & & 0.079 & & \\
2 & $18: 5 \mathrm{n} 3$ & 7.89 & 0.003 & 0.032 & $*$ & 0.43 \\
3 & $18: 5 \mathrm{n} 3$ & 4.35 & 0.008 & 0.016 & $*$ & 0.53 \\
1 & $18: 4 \mathrm{n} 3$ & & & 0.258 & & \\
2 & $18: 4 \mathrm{n} 3$ & 6.13 & 0.002 & 0.027 & $*$ & 0.46 \\
3 & $18: 4 \mathrm{n} 3$ & & & 0.057 & & \\
1 & $20: 5 \mathrm{n} 3$ & & & 0.381 & & \\
2 & $20: 5 \mathrm{n} 3$ & 12.39 & -0.002 & 0.030 & $*$ & 0.44 \\
3 & $20: 5 \mathrm{n} 3$ & & & 0.087 & & \\
1 & $22: 6 \mathrm{n} 3$ & 16.28 & -0.003 & 0.019 & $*$ & 0.51 \\
2 & $22: 6 n 3$ & & & 0.139 & & \\
3 & $22: 6 \mathrm{n} 3$ & 14.85 & 0.006 & 0.004 & $* *$ & 0.67 \\
1 & $18: 1 \mathrm{n} 9$ & 4.483 & 0.001 & 0.008 & $* *$ & 0.60 \\
2 & $18: 1 \mathrm{n} 9$ & & & 0.130 & & \\
3 & $18: 1 \mathrm{n} 9$ & & & 0.930 & & \\
1 & Haptophytes & & & 0.434 & & \\
2 & Haptophytes & 14.021 & 0.005 & 0.011 & $*$ & 0.58 \\
3 & Haptophytes & 9.479 & 0.010 & 0.020 & $*$ & 0.50 \\
\hline & & & & & &
\end{tabular}

respectively, throughout the entire period and in all treatments (Fig. 2). No clear overall trend or obvious differences between the treatments were found in 16:0. However, 16:0 peaked at $17-19 \%$ on day 8 , followed by a rather stable period during phase 2 (16-17.5\%), followed by another peak and a decline towards the last measuring day in phase 3 (Fig. 2). Relatively high (and differing) percentages of 18:0 were found in the first samples (day 4), followed by a clearly decreasing trend, and ending with $2-3 \%$ for all treatments at the end of the investigated period. Amongst the monounsaturated fatty acids (MUFAs), 16:1n7 and 18:1n9 had the highest percentages (on average 5-7\% of total fatty acids, Fig. 2, Table sI), with the highest values of $18: 1 \mathrm{n} 9$ found in the middle of the investigated period (between days 11 and 17), while $16: 1 \mathrm{n} 7$ peaked in the beginning (day 4) and the end (days 23-25), particularly in the low and intermediate $p \mathrm{CO}_{2}$ treatments.
The group-specific fatty acids, which can be used as taxonomic markers, followed the development and decline of the major phytoplankton groups (diatoms, dinoflagellates, chlorophytes/ prasinophytes): the diatom markers $(16: 1 \mathrm{n} 7+16: 4 \mathrm{n} 1+20: 5 \mathrm{n} 3)$ were relatively high in all treatments on day $4(21-27 \%)$, decreased afterwards in all treatments to $12-16 \%$ during the phase between the first and the second bloom (days 11-17), and increased in all treatments towards the end, particularly under low and intermediate $\mathrm{pCO}_{2}$ conditions. The dinoflagellate marker $(18: 4 \mathrm{n} 3+18: 5 \mathrm{n} 3+22: 6 \mathrm{n} 3)$ increased between day 8 and day 21 in the high $p \mathrm{CO}_{2}$ treatments, while it decreased again after day 21 in the mesocosms treated with intermediate or low $p \mathrm{CO}_{2}$ concentrations. The chlorophyte marker $(18: 2 n 6+18: 3 n 3)$ increased from day 4 to 8 , followed by a weakly decreasing trend towards the end of the experimental period in all treatments. Highest values were found under 

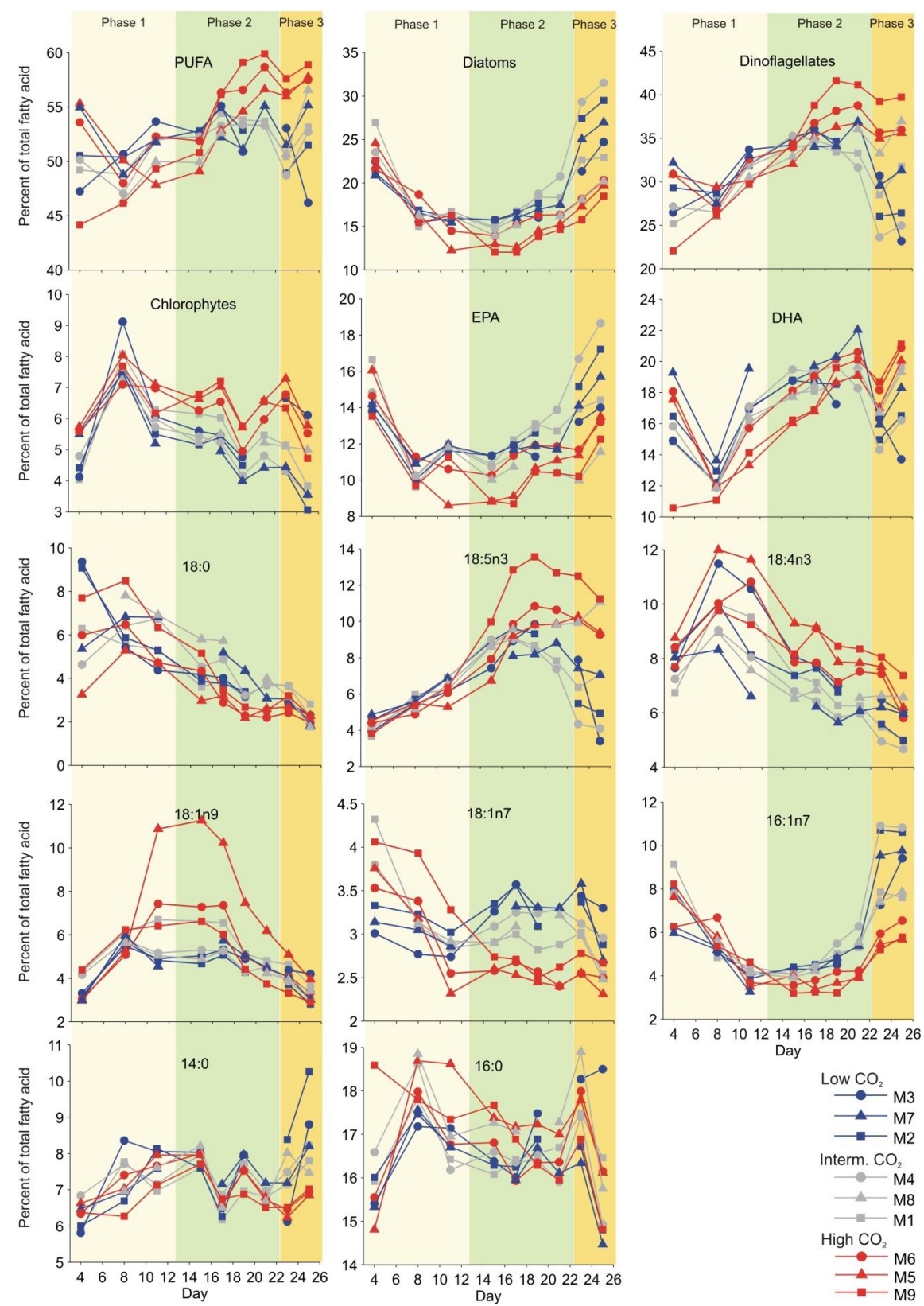

Fig. 2. Temporal development of selected fatty acids (in $\%$ of total fatty acids) during the experiment. Colour coding and experimental phases as in Fig. 1.

high $p \mathrm{CO}_{2}$ conditions, however, the correlation with $p \mathrm{CO}_{2}$ was only significant during phase 2 .

A principal component analysis (PCA) shows that the temporal development of the blooms (i.e. taxonomic changes over time) was the major factor determining the extent of similarity in fatty acid composition among different samples (Fig. 4). In addition, samples from the mesocosms exposed to the highest $p \mathrm{CO}_{2}$ concentrations were (partly) separated from the rest. This separation of the high $p \mathrm{CO}_{2}$ samples from the rest was particularly clear during phase 3 . With respect to dominating fatty acids, the first and last samples were characterized by relatively high percentages of diatom marker fatty acids, samples from the period between bloom phase 1 and 2 displayed increased values of chlorophyte markers, while dinoflagellate markers were most important in samples from the second bloom, as well as in the high $p \mathrm{CO}_{2}$ samples of phase 3 (Fig. 4).

Quantitative fatty acid results (standardized to particulate carbon) are shown in the Supplement (Tables sII and sIII, Figs. sI and sII). The temporal changes and responses to the 


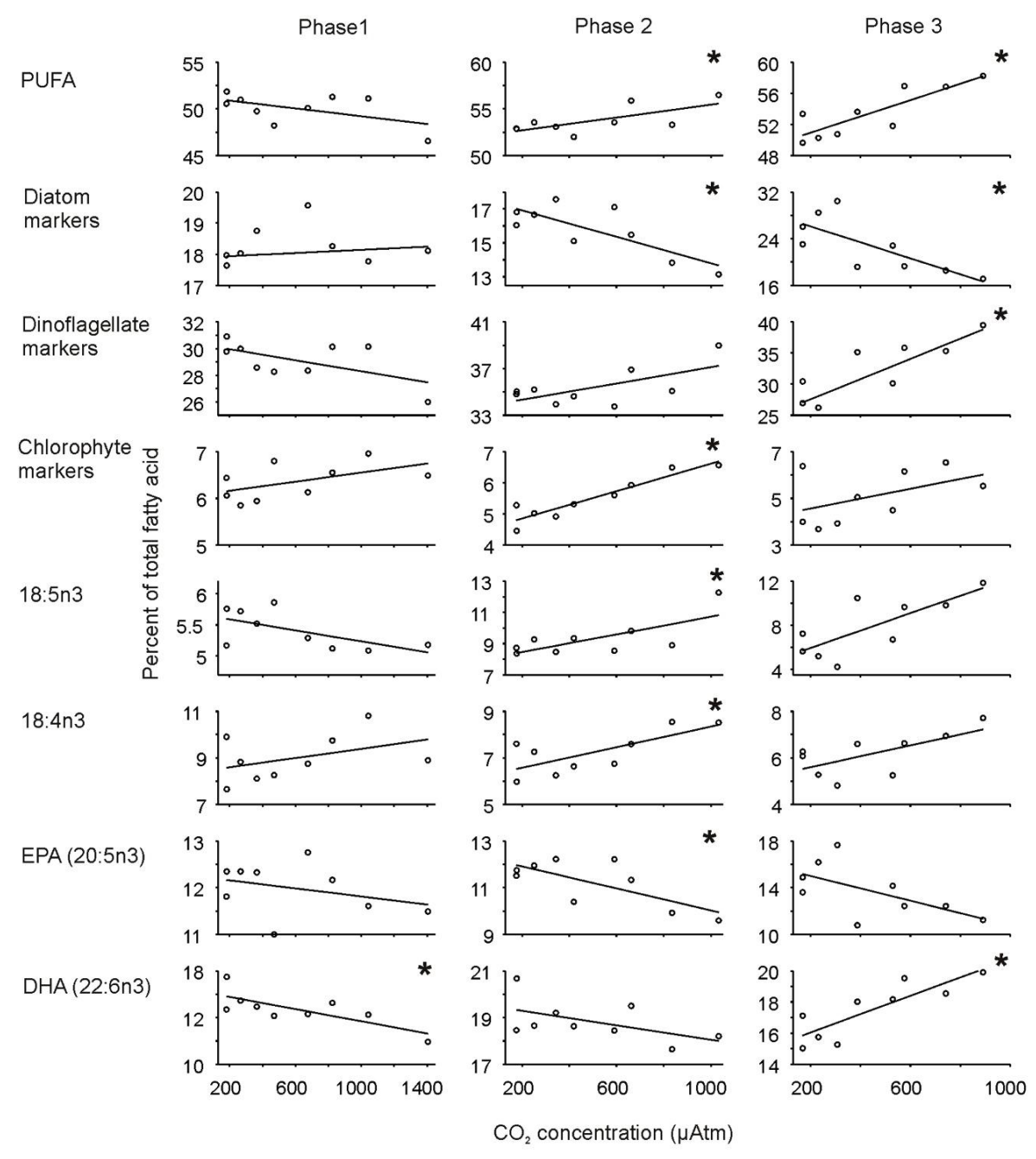

Fig. 3. Relationship between proportions of different fatty acid markers $(\%)$ and $\mathrm{CO}_{2}$ level $(\mu$ atm) in different phases of the experiment. Proportion of different fatty acids markers and $\mathrm{CO}_{2}$ levels were averaged over the time period of the three phases: Phase $1=$ day -4 to 12 , Phase $2=$ day 13 to 21 , Phase $3=$ day 22 to end. linear regressions were fitted to each data set. Asterisks (*) mark those relationships for which the linear regression analysis was statistically significant $(p<0.05$, see Table X2).

applied experimental treatment were in most cases similar to the relative data described in detail. The total amount of fatty acids showed a weak, but not significant, positive trend as a response to increasing $p \mathrm{CO}_{2}$ in all three phases (Fig. sII). The overall amount of PUFAs did not increase as a response to the nutrient addition, and was significantly positively related to $p \mathrm{CO}_{2}$ only during Phase 2 .

\section{Discussion}

This study presents the first analysis of ocean acidification effects on the fatty acid composition of a natural plankton community. Such a study appears to be particularly important for judging the ecological relevance of potential changes in planktonic fatty acid profiles since experiments with unialgal cultures demonstrated extremely varying effects (see in- troduction). Our results provide no indications for a direct negative effect of ocean acidification on essential fatty acids, neither with respect to their absolute nor relative amounts (Table sI, sII, Figs. 3 and sII). As the sole exception, the relative amount of EPA (20:5n3) was significantly negatively correlated with $p \mathrm{CO}_{2}$ during phase 2 . This trend was also negative in phases 1 and 3, but not statistically significant. In terms of absolute amounts of this fatty acid (standardized to particulate carbon), however, there was no significant relation to $p \mathrm{CO}_{2}$ during any of the periods. The strongest positive relations to $p \mathrm{CO}_{2}$ were seen in the C18 PUFAs 18:5n3 and 18:4n3, as well as in DHA (22:6n3) during phase 3. As a result, we also found a positive relation between dinoflagellate marker and overall PUFAs to $p \mathrm{CO}_{2}$. However, to which extent the positive correlation of high $p \mathrm{CO}_{2}$ levels with the overall percentage of PUFAs was caused by a direct effect 


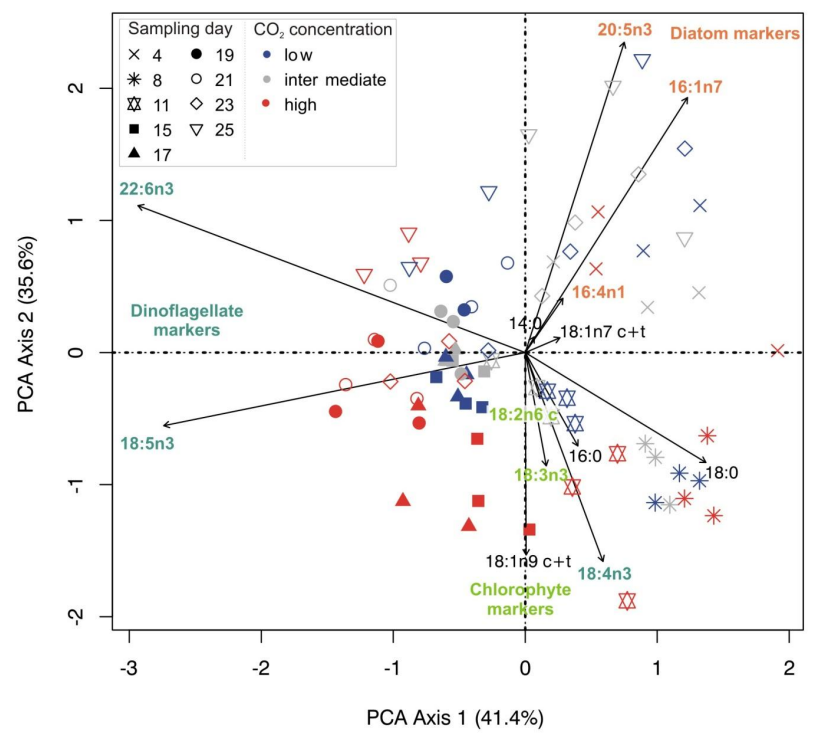

Fig. 4. Biplot of principal component analysis (PCA) based on fatty acid composition in each mesocosm on each sampling day. Individual samples are colour coded according to $p \mathrm{CO}_{2}$ level as in Fig. 1 . Symbols refer to sampling days. The first axis explains $41.4 \%$ of the variation, the second axis $35.6 \%$.

of $\mathrm{CO}_{2}$ on these specific fatty acids or their synthesis, cannot be deduced from a field study addressing the community level only. The simultaneously occurring shifts in species composition overlay the picture. The PCA rather points at taxonomic changes as the most important factor behind the changes in the fatty acid profile, thereby indicating an indirect effect on fatty acid composition, mediated by speciesspecific differences in the response to elevated $p \mathrm{CO}_{2}$ levels. From an ecological point of view, however, it is remarkable that the overall community response with respect to the relative amount of PUFAs to increased $\mathrm{CO}_{2}$ concentrations was rather positive in this experiment. Hence, findings about detrimental effects of ocean acidification on single species in laboratory studies (as, for instance, Riebesell et al. (2000) or Tsuzuki et al. (1990)), and even their consequences for grazers (Rossoll et al., 2012) are probably less relevant in a natural situation where other, more $\mathrm{CO}_{2}$-tolerant species take over. Since grazers are not able to selectively feed upon specific algal species, the overall amount of essential PUFAs available in the entire community (or at least within a certain size class) is the important measure for the algal food quality. This also holds true for the implications for trophic transfer efficiency and consequences for phytoplankton-zooplankton ratios (see Brett and Müller-Navarra (1997), and references therein). EPA and DHA are most efficiently retained in zooplankton and fish (Kainz et al., 2004). In particular, the central role of DHA for the proper development of neurological function has been reported not only from studies related to aquacultural applications (Sargent et al., 1997), but also in a much wider context (Stillwell and Wassall, 2003). It is an important marker fatty acid for dinoflagellates (Dalsgaard et al., 2003) that proved to be the taxonomic group that thrived best under high $p \mathrm{CO}_{2}$ levels (for details about treatment effects on the taxonomic composition, see Schulz et al., 2013).

Apart from the applied $p \mathrm{CO}_{2}$ gradient, also the addition of inorganic nutrients had the potential to affect community fatty acid composition. However, no direct effect of nutrient addition was seen on the overall percentage of PUFAs in the mesocosms exposed to low or intermediate $p \mathrm{CO}_{2}$, while an increase in the relative abundances of PUFAs was found in the high $p \mathrm{CO}_{2}$ treatments (see Fig. 2). The absolute amounts of PUFAs (standardized to $\mathrm{C}_{\text {part }}$ ) did not show any increase during phase 2 at all (see Fig. sII). Previous studies about the impact of nutrient limitation on fatty acid composition have always shown a decrease in PUFAs as a consequence of poor nutrient supply (Roessler, 1988; Reitan et al., 1994). However, the overall percentages of PUFAs in this experiment were rather high, and exceeded even the previously reported PUFA values during the early phase of a spring bloom in Kongsfjorden in 2003 (Leu et al., 2006). This seems surprising given the low inorganic nutrient concentrations measured in the beginning of the experimental period, but can probably be explained by the fact that this situation was characterized by a dominance of nanophytoplankton, utilizing predominantly recycled nutrients (ammonia, DON), made available via grazing and the microbial loop. This implies that the phytoplankton community was not limited by nutrients. The close to Redfield $C: P$ and $C: N$ ratios in particulate organic matter (POM) also confirm the absence of nutrient limitation during the first phase of the experiment (before nutrient addition), despite very low measurable amounts of free inorganic nutrients (Schulz et al., 2013). Since Mayzaud et al. (2013) reported similarly high values of DHA in POM from Kongsfjorden in late June 2007, such a summer situation might in fact be typical in this area.

A strong correlation between the observed dynamics and treatment-dependent differences in planktonic fatty acid profiles with corresponding changes in taxonomic composition became evident when comparing our results with those from colleagues who had performed microscopic and CHEMTAX analyses of the same communities during the experiment (Schulz et al., 2013). They found similar patterns based upon an HPLC analysis of photosynthetic pigments and by traditional microscopic analysis and species identification - at least for the later part of the experimental period. Microscopic analysis and fatty acid composition confirmed an increase of diatom biomass towards the end of the experiment, with highest abundances in the low and intermediate $p \mathrm{CO}_{2}$ treatments. Similarly, the positive response of autotrophic dinoflagellates to high $p \mathrm{CO}_{2}$ in the late phase of the experiment was found with all three methods (see Schulz et al., 2013). Some discrepancies were found, however, during the early phase of the experiment. In particular, the high percentages of diatom marker fatty acids found in samples taken on 
Table 3. Fatty acid (FA) composition (\%) and content (standardized to $\mu \mathrm{g} \mathrm{FA} \mathrm{mg}^{-1} \mathrm{C}$ ) of cirripedia nauplii. Values are averages of three replicates and standard deviation (SD). Each sample was comprised of 120 individuals.

\begin{tabular}{rrrrr}
\hline Fatty acids & Composition $(\%)$ & SD & Content $\left(\mu \mathrm{g} \mathrm{FA} \mathrm{mg}{ }^{-1} \mathrm{C}\right)$ & $\mathrm{SD}$ \\
\hline $14: 0$ & 5.76 & \pm 1.22 & 15.10 & \pm 2.20 \\
$14: 1$ & 0.34 & \pm 0.12 & 0.89 & \pm 0.21 \\
$\mathrm{a}-15: 0$ & 0.55 & \pm 0.38 & 1.44 & \pm 0.69 \\
$15: 0$ & 0.66 & \pm 0.13 & 1.73 & \pm 0.24 \\
$16: 0$ & 20.15 & \pm 2.95 & 52.64 & \pm 5.34 \\
$16: 1 \mathrm{n} 7$ & 10.19 & \pm 2.69 & 26.76 & \pm 4.87 \\
$16: 1 \mathrm{n} 5$ & 0.41 & \pm 0.27 & 1.10 & \pm 0.50 \\
$16: 2 \mathrm{n} 4$ & 0.09 & \pm 0.02 & 0.23 & \pm 0.03 \\
$16: 3 \mathrm{n} 4$ & 0.47 & \pm 0.11 & 1.22 & \pm 0.19 \\
$16: 4 \mathrm{n} 1$ & 0.98 & \pm 0.27 & 2.58 & \pm 0.49 \\
$18: 0$ & 5.99 & \pm 1.40 & 15.42 & \pm 2.54 \\
$18: 1 \mathrm{n} 9 \mathrm{c}+\mathrm{t}$ & 5.91 & \pm 1.11 & 15.48 & \pm 2.01 \\
$18: 1 \mathrm{n} 7$ & 6.43 & \pm 0.79 & 16.81 & \pm 1.43 \\
$18: 2 \mathrm{n} 6 \mathrm{cis}$ & 1.53 & \pm 0.10 & 3.99 & \pm 0.18 \\
$18: 3$ (n6) & 0.28 & \pm 0.09 & 0.73 & \pm 0.16 \\
$18: 3 \mathrm{n} 3$ & 1.03 & \pm 0.13 & 2.69 & \pm 0.24 \\
$18: 4 \mathrm{n} 3$ & 3.79 & \pm 0.87 & 9.94 & \pm 1.58 \\
$20: 1 \mathrm{n} 9$ & 2.35 & \pm 0.36 & 6.14 & \pm 0.66 \\
$20: 0$ & 1.60 & \pm 0.24 & 4.18 & \pm 0.44 \\
$20: 4 \mathrm{n} 6$ & 0.33 & \pm 0.04 & 0.87 & \pm 0.07 \\
$20: 5 \mathrm{n} 3$ & 18.05 & \pm 3.65 & 47.22 & \pm 6.61 \\
$22: 0$ & 0.36 & \pm 0.09 & 0.95 & \pm 0.16 \\
$22: 1 \mathrm{n} 11$ & 0.93 & \pm 0.16 & 2.44 & \pm 0.30 \\
$22: 1 \mathrm{n} 9$ & 0.93 & \pm 0.25 & 2.43 & \pm 0.46 \\
$22: 5 \mathrm{n} 3$ & 0.30 & \pm 0.02 & 0.79 & \pm 0.04 \\
$24: 1 \mathrm{n} 11$ & 0.25 & \pm 0.11 & 0.65 & \pm 0.20 \\
$22: 6 \mathrm{n} 3$ & 9.36 & \pm 2.47 & 24.41 & \pm 4.48 \\
Total FA & & & 258.80 & \pm 22.76 \\
PUFA & 36.21 & \pm 7.20 & 94.66 & \pm 13.04 \\
MUFA & 27.74 & \pm 5.63 & 72.68 & \pm 10.19 \\
SAFA & 35.08 & \pm 3.65 & 91.45 & \pm 6.60 \\
\hline & & & &
\end{tabular}

day 4 could not be related to corresponding result of taxonomic analyses. Rather, they were attributed to the numerous occurrences of cirripedia larvae on that day. These larvae are too small to be efficiently separated from the rest of the particulate organic matter collected on a GF/F-filter when obtaining fatty acid samples of the planktonic community. As described by Niehoff et al. (2013), their abundance peaked about the day when the mesocosms were closed. Thereby, masses of these larval stages were entrapped in the enclosures and found in the water column during the early phase of the experiment. Later on, they sank out of the water column and supposedly started settling on the bottom or the walls of the mesocosms. A separate analysis of their fatty acid composition showed high values for typical membranespecific fatty acids, such as 16:0, EPA and DHA (Table 3). As EPA represents at the same time the most important diatom marker, this explains the misleading conclusion of high percentages of diatom marker fatty acids. To our knowledge, this was the first time ever the fatty acid composition of cirriped nauplii was analysed specifically. Hence, there is no possibility to judge to which extent their specific fatty acid profile was related to their previous dietary uptake of algal fatty acids. We observed them during filtration only in the earliest samples taken for fatty acid analysis. Due to their relatively high biomass (compared to phytoplankton cells), their patchy occurrence in our samples probably also explains the striking variability in the fatty acid composition from different mesocosms on day 4 , which exceeded by far the variability on any other sampling day. This was furthermore confirmed by a considerably higher content of total fatty acids in samples taken on day 4 (up to $250 \mu \mathrm{g}$ FA per mg C vs. 70-160 $\mu \mathrm{g}$ FA per mg C on days without cirripedia "contamination", Table sII) that was similar to the total FA content of cirripeds analyzed separately $(259 \mu \mathrm{g}$ FA per mg C, Table 3$)$. With respect to the dinoflagellate development, we found that the fatty acid results reflected mostly the development of the autotrophic dinoflagellates. According to the HPLC and microscopic analyses, their increase started only after day 14 and 
continued until day 25 in all treatments. It decreased thereafter in the low $\mathrm{CO}_{2}$ treatment, but stayed high in intermediate and high $\mathrm{CO}_{2}$ (Schulz et al., 2013). This was well in accordance with a corresponding increase of dinoflagellate marker fatty acids during the same period. For heterotrophic dinoflagellates, microscopic analysis indicated that they were abundant throughout the experiment and did not differ much among treatments. Overall, the treatment-induced change in planktonic community composition led indirectly to a shift in community fatty acid composition - but without a net negative development of the physiologically and ecologically important essential PUFAs.

\section{Conclusions}

We found no indications for a negative effect of ocean acidification on the nutritional quality of particulate matter in terms of its overall content in essential PUFAs. The applied $p \mathrm{CO}_{2}$ gradient, however, did affect the taxonomic composition of the phytoplankton community (particularly during the last phase of the study), resulting in corresponding differences in fatty acid composition among $p \mathrm{CO}_{2}$ treatments. Hence, the overall availability of essential PUFAs for higher trophic levels seems not to be affected negatively, although the specific fatty acid composition may change. It seems more likely, however, that other factors, most of all a change in average size distribution among phytoplankton due to taxonomic changes, will have a greater impact on the food web structure than the mere fatty acid composition of the community.

\section{Supplementary material related to this article is available online at: http://www.biogeosciences.net/10/ 1143/2013/bg-10-1143-2013-supplement.pdf.}

Acknowledgements. This work is a contribution to the "European Project on Ocean Acidification" (EPOCA) which received funding from the European Community's Seventh Framework Programme (FP7/2007-2013) under grant agreement no. 211384. We gratefully acknowledge the logistical support of Greenpeace International for its assistance with the transport of the mesocosm facility from Kiel to Ny-Ålesund and back to Kiel. We also thank the captains and crews of $\mathrm{m} / \mathrm{V}$ Esperanza of Greenpeace and R/V Viking Explorer of the University Centre in Svalbard (UNIS) for assistance during mesocosm transport and during deployment and recovery in Kongsfjorden. We thank the staff of the French-German Arctic Research Base at Ny-Ålesund, in particular Marcus Schumacher, for on-site logistical support. We are grateful to Martin Graeve for his support of the fatty acid analysis, and to Barbara Niehoff for the collection and sorting of cirripedia nauplii. Financial support for E. Leu and m. Daase was provided by the Norwegian Research Council through project grant no. 184860 (MERCLIM).

Edited by: T. F. Thingstad

\section{References}

Ackman, R. G., Tocher, C. S., and McLachlan, J.: Marine phytoplankter fatty acids, J. Fish. Res. Board Can., 25, 1603-1620, 1968.

Bellerby, R. G. J., Silyakova, A., Nondal, G., Slagstad, D., Czerny, J., De Lange, T., and Ludwig, A.: Marine carbonate system evolution during the epoca arctic pelagic ecosystem experiment in the context of simulated future arctic ocean acidification, Biogeosciences, accepted 10, 2013.

Brett, M. T. and Müller-Navarra, D. C.: The role of highly unsaturated fatty acids in aquatic food web processes, Freshwater Biol., 38, 483-499, 1997.

Broecker, W. S., Takahashi, T., Simpson, H. J., and Peng, T. H.: Fate of fossil fuel carbon dioxide and the global carbon budget, Science, 26, 409-418, 1979.

Brussaard, C. P. D., Noordeloos, A. A. M., Witte, H., Collenteur, M. C. J., Schulz, K., Ludwig, A., and Riebesell, U.: Arctic microbial community dynamics influenced by elevated $\mathrm{CO}_{2}$ levels, Biogeosciences, 10, 719-731, doi:10.5194/bg-10-719-2013, 2013.

Carvalho, A. P. and Malcata, F. X.: Optimization of omega-3 fatty acid production by microalgae: Crossover effects of co 2 and light intensity under batch and continuous cultivation modes, Marine Biotechnol., 7, 381-388, 2005.

Dalsgaard, J., St John, M., Kattner, G., Muller-Navarra, D., and Hagen, W.: Fatty acid trophic markers in the pelagic marine environment, Adv. Mar. Biol., 46, 225-340, 2003.

Fiorini, S., Gattuso, J.-P., van Rijswijk, P., and Middelburg, J.: Coccolithophores lipid and carbon isotope composition and their variability related to changes in seawater carbonate chemistry, J. Exp. Mar. Biol. Ecol., 394, 74-85, doi:10.1016/j.jembe.2010.07.020, 2010.

Folch, J., Lees, M., and Sloane Stanley, G. H.: A simple method for isolation and purification of total lipids from animal tissue, J. Biol. Chem., 226, 497-509, 1957.

Hoshida, H., Ohira, T., Minematsu, A., Akada, R., and Nishizawa, Y.: Accumulation of eicosapentaenoic acid in nannochloropsis $\mathrm{sp}$ in response to elevated co2 concentrations, J. Appl. Phycol., 17, 29-34, 10.1007/s10811-005-5512-9, 2005.

Jonasdottir, S. H., Trung, N. H., Hansen, F., and Gartner, S.: Egg production and hatching success in the calanoid copepods calanus helgolandicus and calanus finmarchicus in the north sea from march to september 2001, J. Plankton Res., 27, 1239-1259, 2005.

Jonasdottir, S. H., Visser, A. W., and Jespersen, C.: Assessing the role of food quality in the production and hatching of temora longicornis eggs, Mar. Ecol. Prog. Ser., 382, 139-150, 2009.

Kainz, M., Arts, M. T., and Mazumder, A.: Essential fatty acids in the planktonic food web and their ecological role for higher trophic levels, Limnol. Oceanogr., 49, 1784-1793, 2004.

Klein Breteler, W. C. M., Schogt, N., and Rampen, S.: Effect of diatom nutrient limitation on copepod development: Role of essential lipids, Mar. Ecol. Prog. Ser., 291, 125-133, 2005.

Leu, E., Falk-Petersen, S., Kwasniewski, S., Wulff, A., Edvardsen, K., and Hessen, D. O.: Fatty acid dynamics during the spring bloom in a high arctic fjord: Importance of abiotic factors versus community changes, Can. J. Fish. Aquat. Sci., 63, 2760-2779, 2006. 
Leu, E., Wiktor, J., Søreide, J. E., Berge, J., and Falk-Petersen, S.: Increased irradiance reduces food quality of sea ice algae, Mar. Ecol. Prog. Ser., 411, 49-60, 2010.

Lischka, S., Buedenbender, J., Boxhammer, T., and Riebesell, U.: Impact of ocean acidification and elevated temperatures on early juveniles of the polar shelled pteropod limacina helicina: Mortality, shell degradation, and shell growth, Biogeosciences, 8, 919932, doi:10.5194/bg-8-919-2011, 2011.

Mayzaud, P., Boutoute, M., and Gasparini, S.: Differential response of fatty acid composition in the different lipid classes from naturally occurring particulate organic matter during spring and summer in a high arctic fjord (Kongsfjorden, svalbard), Mar. Biol., 160, 383-398, 2013.

Müller-Navarra, D. C.: Food web paradigms: The biochemical view on trophic interactions, Int. Rev. Hydrobiol., 93, 489-505, doi:10.1002/iroh.200711046, 2008.

Niehoff, B., Wolf, T., Czerny, J., and Boxhammer, T.: Mesozooplankton community development at elevated $\mathrm{CO}_{2}$ concentrations: Results from a mesocosm experiment in a high arctic fjord, Biogeosciences, accepted, 10, 2013.

Pond, D., Harris, R., Head, R., and Harbour, D.: Environmental and nutritional factors determining seasonal variability in the fecundity and egg viability of calanus helgolandicus in coastal waters off plymouth, uk, Mar. Ecol. Prog. Ser., 143, 45-63, 1996.

Reitan, K. I., Rainuzzo, J. R., and Olsen, Y.: Effect of nutrient limitation on fatty acid and lipid content of marine microalgae, J. Phycol., 30, 972-979, 1994.

Riebesell, U., Revill, A. T., Holdsworth, D. G., and Volkman, J. $\mathrm{K}$.: The effects of varying $\mathrm{CO}_{2}$ concentration on lipid composition and carbon isotope fractionation in emiliania huxleyi, Geochim. Cosmochim. Ac., 64, 4179-4192, doi:10.1016/s00167037(00)00474-9, 2000.

Riebesell, U., Bröckel, K., Büdenbender, J., Czerny, J., Deckelnick, M., Hoffmann, D., Lenz, U., Ludwig, A., and Schulz, K. G.: A mobile, free-floating mesocosm platform for in situ experimentation, Biogeosciences, in preparation, 2013.

Roessler, P. G.: Effects of silicon deficiency on lipid composition and metabolism in the diatom cyclotella cryptica, J. Phycol., 24, 394-400, 1988.

Rossoll, D., Bermudez, R., Hauss, H., Schulz, K. G., Riebesell, U., Sommer, U., and Winder, M.: Ocean acidification-induced food quality deterioration constrains trophic transfer, PLoS ONE, 7, e34737, 2012.
Sargent, J. R., Bell, J. G., Bell, M. V., Henderson, R. J., and Tocher, D. R.: Dietary origins and functions of long-chain (n-3) polyunsaturated fatty acids in marine fish, J. Mar. Biotechnol., 3, 26-28, 1995.

Sargent, J. R., McEvoy, L. A., and Bell, J. G.: Requirements, presentation and sources of polyunsaturated fatty acids in marine fish larval feeds, Aquaculture, 155, 117-127, 1997.

Schulz, K. G., Bellerby, R. G. J., Brussaard, C. P. D., Büdenbender, J., Czerny, J., Fischer, M., Koch-Klavsen, S., Krug, S., Lischka S., Ludwig, A., M., M., Nondal, G., Silyakova, A., Stuhr, A., and Riebesell, U.: Temporal biomass dynamics of an arctic plankton bloom in response to increasing levels of atmospheric carbon dioxide, Biogeosciences, 10, 161-180, 2013, http://www.biogeosciences.net/10/161/2013/.

Steinacher, M., Joos, F., Frölicher, T. L., Plattner, G. K., and Doney, S. C.: Imminent ocean acidification in the arctic projected with the ncar global coupled carbon cycle-climate model, Biogeosciences, 6, 515-533, 2009, http://www.biogeosciences.net/6/515/2009/.

Stillwell, W. and Wassall, S. R.: Docosahexaenoic acid: Membrane properties of a unique fatty acid, Chem. Phys. Lipids, 126, 1-27, 2003.

Svendsen, H., Beszczynska-Moeller, A., Hagen, J. O., Lefauconnier, B., Tverberg, V., Gerland, S., Oerbaek, J. B., Bischof, K., Papucci, C., Zajaczkowski, M., Azzolini, R., Bruland, O., Wiencke, C., Winther, J. G., and Dallmann, W.: The physical environment of kongsfjorden-krossfjorden, an arctic fjord system in svalbard, Polar Res., 21, 133-166, 2002.

Thompson, P. A., Harrison, P. J., and Whyte, J. N. C.: Influence of irradiance on the fatty acid composition of phytoplankton, J. Phycol., 26, 278-288, 1990.

Thompson, P. A., Guo, M. X., Harrison, P. J., and Whyte, J. N. C. Effects of variation in temperature on the fatty acid composition of 8 species of marine phytoplankton, J. Phycol., 28, 488-497, 1992.

Tsuzuki, M., Ohnuma, E., Sato, N., Takaku, T., and Kawaguchi, A.: Effects of $\mathrm{co} 2$ concentration during growth on fatty acid composition in microalgae, Plant Physiol., 93, 851-856, doi:10.1104/pp.93.3.851, 1990.

Watanabe, T., Tamiya, T., Oka, A., Hirata, M., Kitajima, C., and Fujita, S.: Improvement of dietary value of live foods for fish larvae by feeding them on omega-3 highly unsaturated fatty-acids and fat soluble vitamins, B. Jpn. Soc. Sci. Fish., 49, 471-479, 1983.

Welschmeyer, N. A.: Fluorometric analysis of chlorophyll a in the presence of chlorophyll $\mathrm{b}$ and pheopigments, Limnol. Oceanogr., 39, 1985-1992, 1994. 